\title{
Variation of Surface Refractivity with Soil Permittivity and Leaf Wetness in a Tropical Location
}

\author{
Adedayo Kayode $^{\mathrm{a}}$, Ashidi Ayodeji ${ }^{\mathrm{a},}$, Oni Samuel ${ }^{\mathrm{a}, \mathrm{b}}$, , Ajewole Moses $^{\mathrm{a}}$ \\ ${ }^{a}$ Department of Physics, Federal University of Technology, Akure, Nigeria. \\ ${ }^{b}$ Department of Physics, College of Education, Ikere-Ekiti, Ekiti State, Nigeria
}

Received: 03 May 2019; Accepted: 06 June 2019; Published: 08 July 2019

\begin{abstract}
Radio signal transmitting above the ground surface experiences attenuation as a result of absorption by vegetation and hydrometeors, refraction due to turbulence in weather parameters; and reflection from ground surface. In this study, attempt was made to compute surface refractivity from its constituent parameters, and investigate its variation with leaf wetness and soil permittivity, at seven (7) different stations across Ondo state, Nigeria. Data for the research were obtained by in-situ measurement using Davis 3125 Vantage Pro2 weather station having sensors for measuring temperature, pressure, relative humidity, leaf wetness and soil moisture content. Measurement was carried out round the clock at 10 minutes integration time for a period of two weeks at each of the study locations, and for each of rainy and dry seasons. The soil moisture content was obtained at $30 \mathrm{~cm}$ soil depth while leaf wetness was measured by attaching its sensor directly to a projected leaf-branch; and surface refractivity was computed from pressure, temperature and humidity data. Correlation analysis was employed to measure the strength and direction of the relationship between surface refractivity and each of soil permittivity and leaf wetness. Across the locations, R ranges from 0.38 to 0.9 ; and 0.04 to 0.7 for rainy and dry season respectively. The value of $\mathrm{R}$ is statistically significant at all the stations during the rainy season and majority of the stations during the dry season; signifying that surface refractivity exhibits good spatial and temporal relationship with soil permittivity and leaf wetness across the stations albeit with varying intensities.
\end{abstract}

Index Terms: Refractivity, Permittivity, Leaf wetness, Temperature and Moisture.

(C) 2019 Published by MECS Publisher. Selection and/or peer review under responsibility of the Research Association of Modern Education and Computer Science

\footnotetext{
* Corresponding author. Tel.:

E-mail address: agashidi@futa.edu.ng
} 


\section{Introduction}

For planning, budgeting and deployment of microwave communication links, it is important to understand the various factors that affect radio wave propagation in any given location. Electromagnetic wave propagating within the troposphere is susceptible to degradation due to absorption by hydrometeors, reflection from the ground surface and atmospheric refraction among others [1]. These phenomena can be characterized in part from the knowledge of the local climate and the weather parameters. One of the most common ways of characterizing the effect of local climate on propagation is through the computation of radio refractivity [2]. At frequencies below $10 \mathrm{GHz}$, radio waves show different degrees of bending in the atmosphere depending on the prevailing atmospheric conditions [3]. Also, leaves being part of the basic components of any vegetation canopy, whose moisture content act as electromagnetic scatterer, must be modelled to determine the total reflectivity of any given vegetation canopy. As the moisture content of leaf branches show significant diurnal and seasonal variations, their dielectric properties are also strongly time dependent [4]. Another parameter of interest to surface wave propagation is the moisture content of soil, whose variation with the waves' dielectric constant is useful for the interpretation of data obtained by various sensors for microwave remote sensing applications in agriculture, hydrology and meteorology [5]. Lastly, due to the presence of gases like oxygen and water vapour which have electric dipole moments, the troposphere has a dielectric constant and hence a refractive index [6]. The prevailing conditions of a local weather in terms of varying temperature, pressure and humidity determines the extent to which a signal will bend towards or away from the radio horizon in a phenomenon known as refractivity [1].

The attenuation of a ground-wave signal with respect to distance depends on the electrical characteristics of the ground and the frequency of the propagating radio signal. Transmission of waves over surfaces with high conductivity such as the sea often experiences lower attenuation. Vegetation is often accorded the least attention while profiling the many factors responsible for signal losses in a propagation channel. Depending on whether the propagation terrain is open or forested, the effect of vegetation can significantly increase the power loss by the communication system. Although the level of attenuation is still a function of the signal frequency and wave propagation angle. Moreover, thick trees that are capable of obstructing vision can be modelled as solid obstruction whose attenuating effect can be analysed using knife edge diffraction techniques; and, with deciduous trees as case study, the effect of vegetation on a radio path exhibited seasonal variation [7]. When a radio antenna is raised above trees and other vegetation, the prediction of emanating field strengths depends upon the estimation of the height of the antenna above areas of reflection and the reflection coefficients [8].

Independent studies have been carried out on many of the factors responsible for signal losses in a propagation channel, but evaluation of the concurrent variation in surface refractivity, soil permittivity and leaf wetness; which can give insight into propagation characteristics such as ground conductivity or reflectivity; scattering or absorption by vegetation; and refraction by tropospheric inhomogeneity; has not been well covered in literature. Consequently, this study attempts to statistically characterize the relationship in the variation pattern of surface refractivity, leaf wetness and soil permittivity on diurnal and seasonal basis. This is important for terrestrial radio link design and planning since these phenomena have micro and macro effects on absorption, reflection and bending of radio signals within the troposphere $[8,9$, and 1].

\section{Review of Relevant Studies}

Several works on tropospheric refractivity have been conducted in Nigeria [10, 11, 12, 13, 14, and 15] among others. The authors reported diurnal and seasonal variation of refractivity, its dependence on moisture and temperature inversion, and the prevalence of super-refractive phenomenon. The effect of hydrometeors on quality of propagation have also been well detailed in literature for tropical regions, some of which include [16, 17, 18, 19, 20 and 21] among others. Wang and Schmugge [22] Vyas [23], and Hallikainen et al., [24], have equally reported that an increase in moisture content in the soil provides a tool to determine soil electrical parameter. The effect of relative dielectric permittivity of soil on AM and FM stations over Southwestern 
Nigeria has been reported [25]. Severe attenuation of signals was observed and artificial ground screen recommended. Ajewole and Arogunjo [9] measured the ground electrical conductivity and obtained a relationship with transmitted power for AM stations in Southwestern Nigeria. Also, Vernier, [26] reported that at about $1000 \mathrm{MHz}$, attenuation is lower for horizontally polarized signal than vertically polarized one. Following limited research output exploring the concurrent variation of radio refractivity with soil permittivity and leaf wetness for microwave design and propagation, this study was conceived to bridge that gap as much as possible.

\section{Research Site and Methodology}

The research was conducted at seven randomly selected locations spread across six local government areas and the three senatorial districts of Ondo State to examine the spatial and temporal distribution of surface refractivity, leaf wetness and soil permittivity. The State lies in the south western part of Nigeria with a climate that typifies a tropical region. The region exhibits two clear climatic seasons (rainy and dry) every year spanning November to March and April to October respectively [27]. Attempt was made to ensure a good degree of uniformity in the geographical characteristics of the measurement spot at all the locations. Hence due consideration was given to similarity in vegetation cover, soil types and texture, mineral deposits and other geological features such as presence of large water bodies, rocks, mountains and hills. Spots having sandy soil with smooth texture and fine structure were used and those with obvious differences in their features were jettisoned. Figure 1 shows the map of Ondo State with the study location while Table 1 shows the coordinates of the locations.

Data for this research were obtained by in-situ measurement using Davis 3125 Vantage Pro2 weather station. It has sensors for measuring temperature, pressure, and relative humidity; two sensors for leaf wetness; and three sensors for soil moisture content. Three sensors were positioned at $30 \mathrm{~cm}, 40 \mathrm{~cm}$ and $50 \mathrm{~cm}$ soil depths to measure soil moisture content which was used to compute soil permittivity, however only the readings from the topmost sensor (30 cm depth) were considered for this study. Leaf wetness was measured directly by attaching its sensors to a projected leaf-branch; and the readings from the two sensors were extracted and averaged. The equipment was calibrated to $\log$ data at 10 minutes interval; and not less than two weeks of continuous measurement was done at all the locations for each of wet and dry seasons. Averaged value of each parameter for the measurement period was employed in the analysis. Soil permittivity and surface refractivity were computed using equation (1) and (3) respectively. Table 2 presents a data acquisition schedule, showing the period of measurement for all the locations during each of rainy and dry seasons.

Soil permittivity $\left(S_{P}\right)$ was evaluated using Topp's model given by Topp et al.,[28] and expressed in (1) as:

$$
S_{P}=3.03+9.30 \theta_{v}+146 \theta_{v}^{2}-76.7 \theta_{v}^{3}
$$

where $\theta_{v}$ is the volumetric moisture content.

This Topp model was adopted because it accommodates the various types of soil classifications and the moisture content values of all the locations visited. The soil moisture content, measured in centibar, was then converted to volumetric moisture content using equation (2):

$$
\theta_{v}=K+0.09807 \times 10^{-2} m^{3} m^{-3}
$$

The volumetric moisture content is the ratio of the volume of water present in a soil sample to the total volume of the soil sample. Surface refractivity values were computed using equation (3): 


$$
N=77.6 \frac{P}{T}+3.73 \times 10^{3} \frac{e}{T^{2}}
$$

where $\mathrm{N}$ represents surface refractivity (N-unit), $\mathrm{P}$ is atmospheric pressure $(\mathrm{hPa}), \mathrm{T}$ is temperature $(\mathrm{K})$ and $\mathrm{e}$ is water vapour pressure $(\mathrm{hPa})$ which is computed from relative humidity and Celsius temperature as given by equation (4):

$$
e=H \times \frac{6.1121 \exp \left(\frac{17.502 t}{t+240.97}\right)}{100}
$$

where $\mathrm{H}$ is relative humidity $(\%)$ and $\mathrm{t}$ is Celsius temperature $\left({ }^{\circ} \mathrm{C}\right)$

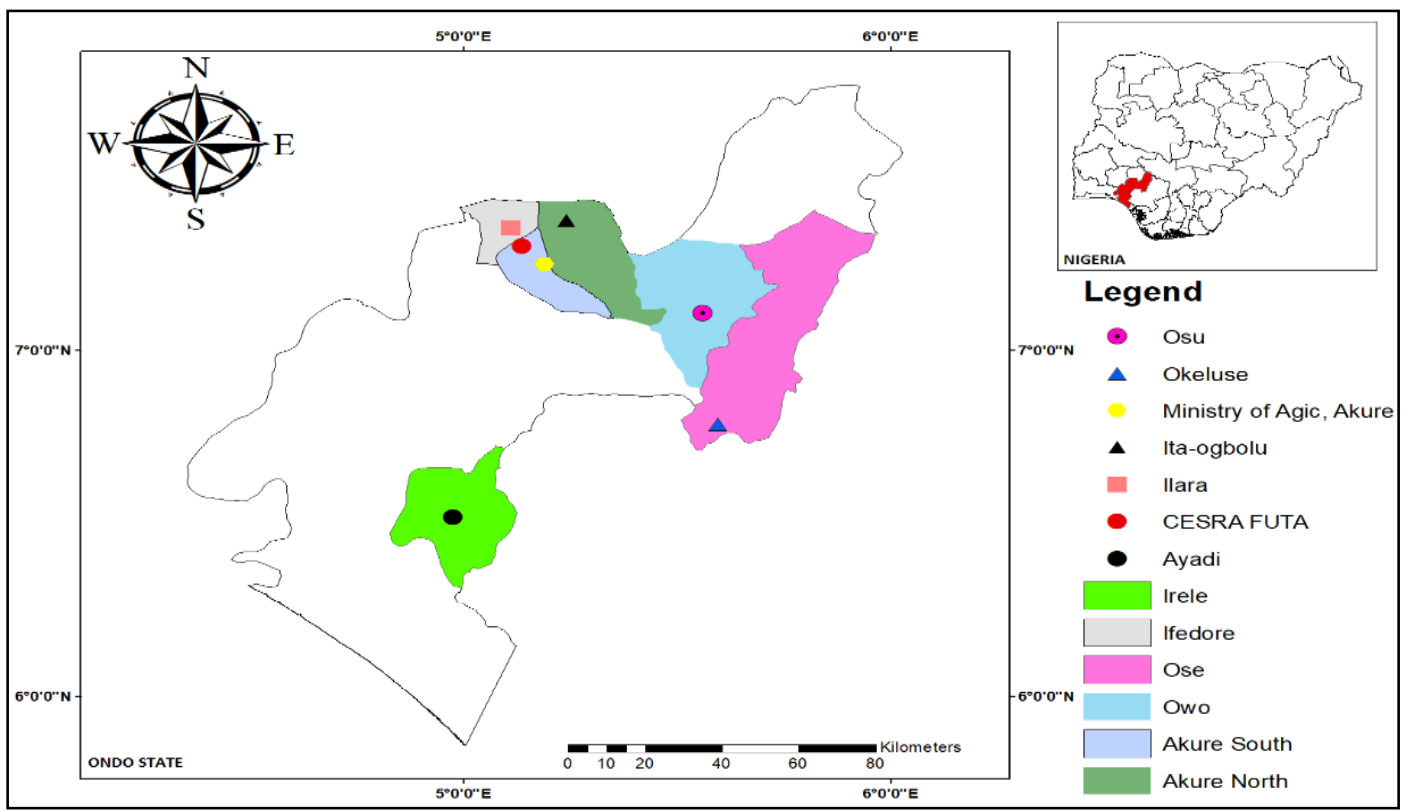

Fig.1. Map of Ondo state showing the study locations

\begin{tabular}{|c|c|c|}
\hline Stations & Designation & Coordinates (Elevation; Latitude; Longitude) \\
\hline Ayadi & Sta_1 & $030.0 \mathrm{~m} ; \mathrm{N} 06.52^{\circ} ; \mathrm{E} 004.98^{\circ}$ \\
\hline Ita-Ogbolu & Sta_2 & $322.9 \mathrm{~m} ; \mathrm{N} 07.38^{\circ} ; \mathrm{E} 005.24^{\circ}$ \\
\hline Ministry of Agriculture & Sta_3 & $344.0 \mathrm{~m} ; \mathrm{N} 07.25^{\circ} ; \mathrm{E} 005.19^{\circ}$ \\
\hline Uso & Sta 4 & $340.0 \mathrm{~m} ; \mathrm{N} 07.11^{\circ} ; \mathrm{E} 005.56^{\circ}$ \\
\hline Okeluse & Sta_5 & $037.7 \mathrm{~m} ; \mathrm{N} 06.79^{\circ} ; \mathrm{E} 005.59^{\circ}$ \\
\hline Ilara Mokin & Sta_6 & $386.8 \mathrm{~m} ; \mathrm{N} 07.36^{\circ} ; \mathrm{E} 005.11^{\circ}$ \\
\hline CESRA(FUTA) & Sta_7 & $386.5 \mathrm{~m} ; \mathrm{N} 07.30^{\circ} ; \mathrm{E} 005.14^{\circ}$ \\
\hline
\end{tabular}

Table 1. Research site, designation and coordinates 
Table 2. Data Acquisition Schedule

\begin{tabular}{|l|l|l|l|l|l|l|l|}
\hline Station & Ayadi & Ita-Ogbolu & $\begin{array}{l}\text { Min of } \\
\text { Agriculture }\end{array}$ & Uso & Okeluse & $\begin{array}{l}\text { Ilara } \\
\text { Mokin }\end{array}$ & CESRA \\
\hline $\begin{array}{l}\text { Period } \\
\text { Rainy } \\
\text { season) }\end{array}$ & $\begin{array}{l}\text { May 01 } \\
\text { to } \\
\text { May 16 }\end{array}$ & $\begin{array}{l}\text { May17 } \\
\text { to } \\
\text { Jun 01 }\end{array}$ & $\begin{array}{l}\text { Jun 02 } \\
\text { to } \\
\text { Jun 16 }\end{array}$ & $\begin{array}{l}\text { Jun 17 } \\
\text { to } \\
\text { Jul 02 }\end{array}$ & $\begin{array}{l}\text { Jul 03 } \\
\text { to } \\
\text { Jul 18 }\end{array}$ & $\begin{array}{l}\text { July 19 } \\
\text { to } \\
\text { Aug 03 }\end{array}$ & $\begin{array}{l}\text { Sep 01 } \\
\text { to } \\
\text { Sep 17 }\end{array}$ \\
\hline $\begin{array}{l}\text { Period (Dry } \\
\text { season) }\end{array}$ & $\begin{array}{l}\text { Dec 02 } \\
\text { to } \\
\text { Dec 17 }\end{array}$ & $\begin{array}{l}\text { Dec 18 } \\
\text { to } \\
\text { Jan 02 }\end{array}$ & $\begin{array}{l}\text { Jan 03 } \\
\text { to } \\
\text { Jan 18 }\end{array}$ & $\begin{array}{l}\text { Jan 19 } \\
\text { to } \\
\text { Feb 02 }\end{array}$ & $\begin{array}{l}\text { Feb 03 } \\
\text { to } \\
\text { Feb 18 }\end{array}$ & $\begin{array}{l}\text { Feb 19 } \\
\text { to } \\
\text { Mar 06 }\end{array}$ & $\begin{array}{l}\text { Mar 07 } \\
\text { to } \\
\text { Mar 22 }\end{array}$ \\
\hline
\end{tabular}

Correlation analysis was used to examine the relationship between surface refractivity $\left(\mathrm{N}_{\mathrm{s}}\right)$ and each of soil permittivity (SP) and leaf wetness (LW); while multivariate regression was used to develop a linear empirical model for the dependence of surface refractivity on soil permittivity and leaf wetness. Selected statistical indicators $-\mathrm{R}$, multiple $\mathrm{R}, \mathrm{R}^{2}$ and Adjusted $\mathrm{R}^{2}$ were employed to evaluate the strength and direction of the relationship between the parameters, as well as the reliability of the empirical model [29, 30, 31, 32 and 33].

\section{Result and Discussion}

Variations of surface refractivity, leaf wetness and soil permittivity were examined on both diurnal and seasonal scales across the seven stations. Figures 2 and 3 show the distribution of surface refractivity at all the stations for the wet and dry season respectively.

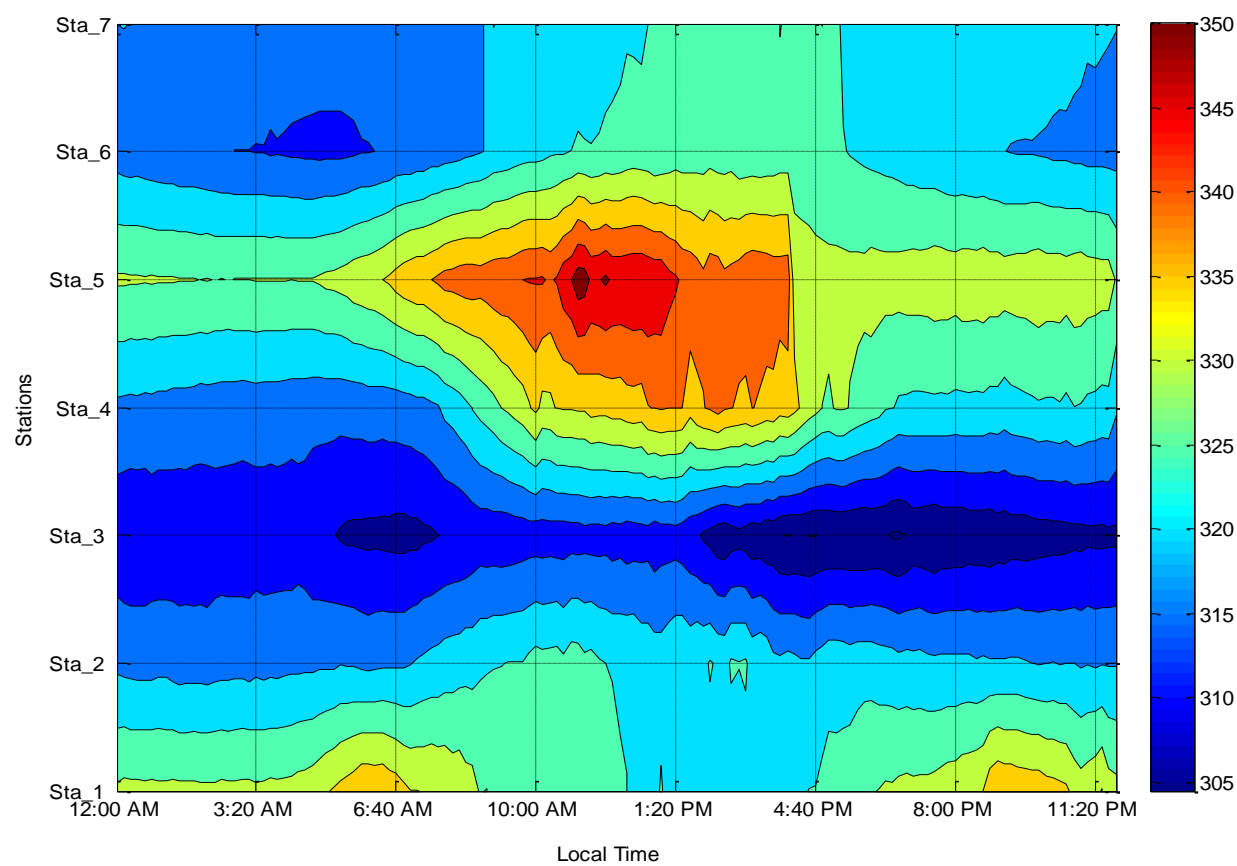

Fig.1. Diurnal variation of surface refractivity across the seven stations during the wet season 


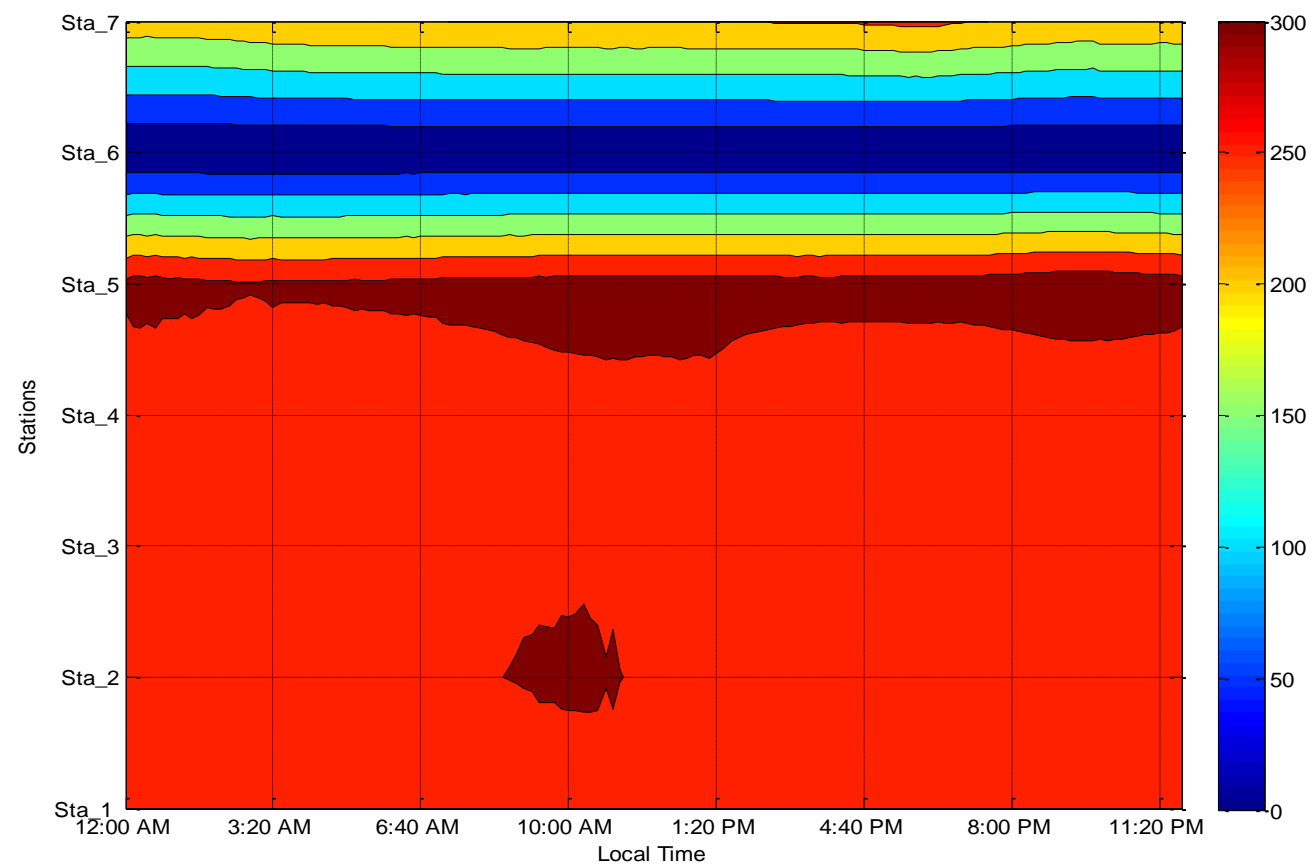

Fig.2. Diurnal variation of surface refractivity across the seven stations during the dry season

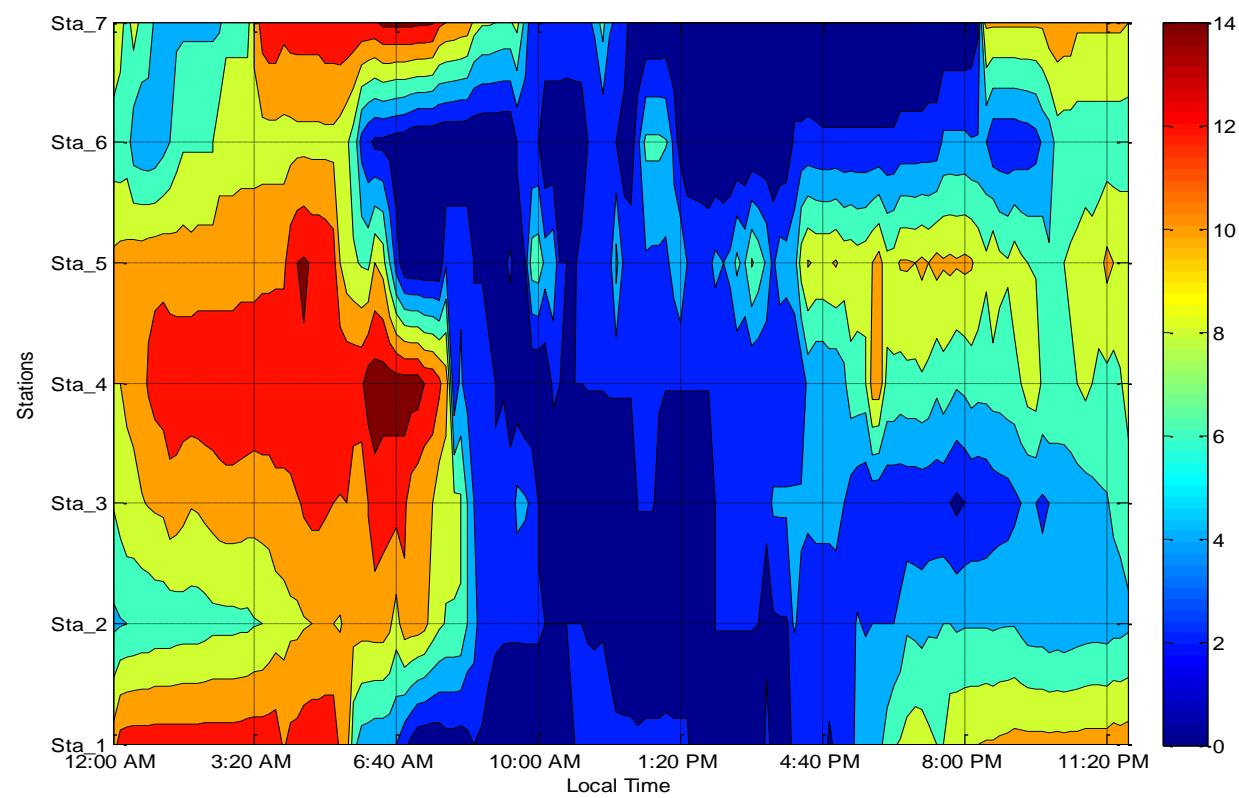

Fig.3. Diurnal variation of leaf wetness across the seven stations during the wet season 
Refractivity values were generally higher during the wet season than in the dry season, as well as during the late evenings, night and early morning hours than afternoon and early evening hours of the day. This is due to the abundance of tropospheric water vapour content/humidity during this period compared to dry season and afternoon period that are synonymous with intense solar activity. The pattern of distribution observed during the wet season were significantly different from dry season. The peak and off peak values of refractivity were recorded during periods of low and high solar/sunshine activity respectively. Slight variations were observed from one station to another. The variation may be attributed to random pattern of rainfall distribution experienced across the study locations during the period under review. Loss of data was experienced at Sta_6 (Ilara Mokin) during the dry season. This explains why value of $0 \mathrm{~N}$-unit was recorded at the station throughout. Figures 4 and 5 show the distribution of leaf wetness at all the stations for the wet and dry season respectively.

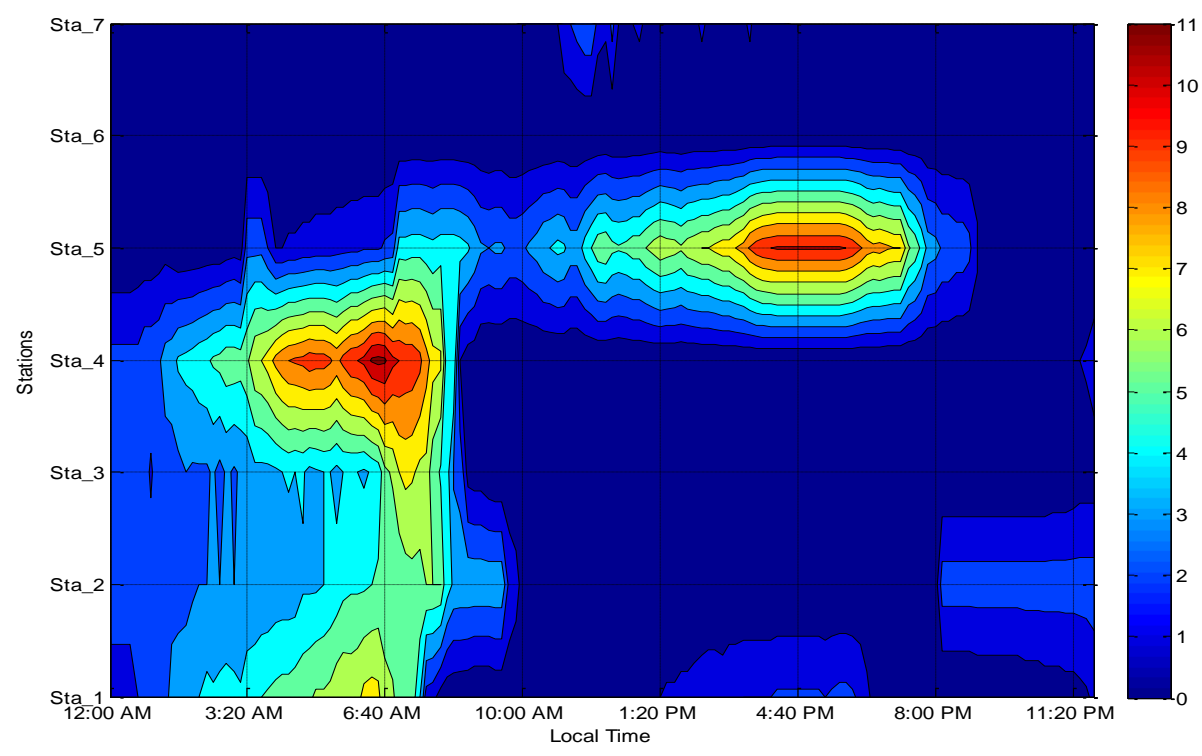

Fig.4. Diurnal variation of leaf wetness across the seven stations during the dry season

The trend is such that high values of leaf wetness were maintained from midnight till dawn, from where it slopes down sharply until it attains the off peak values during the afternoon period. It then stays within the low region till late afternoon/early evening hours when the values began to appreciate. For both seasons, this trend was common except for occasional deviations experienced from one station to another. These are indicative of the variation in weather conditions across the different stations. Expectedly, during the wet season, the time interval during which low values were recorded, the intensity of the values, and the periods during which the values appreciated and depreciated; all varied from one station to another. This is in response to randomness in rainfall distribution across the stations. However for the dry season, the values increased steadily from midnight and peaked around dawn, then began to decrease sharply to the off peak value (mostly zero) which was maintained till late evening when upward trend was restored.

Since soil water content is the major variable that determines soil permittivity, this fact became obvious in the observed distribution pattern. Figures 6 and 7 show the distribution of soil permittivity at all the stations for the wet and dry seasons respectively. The values recorded during the wet season were significantly higher than those of the dry season. 


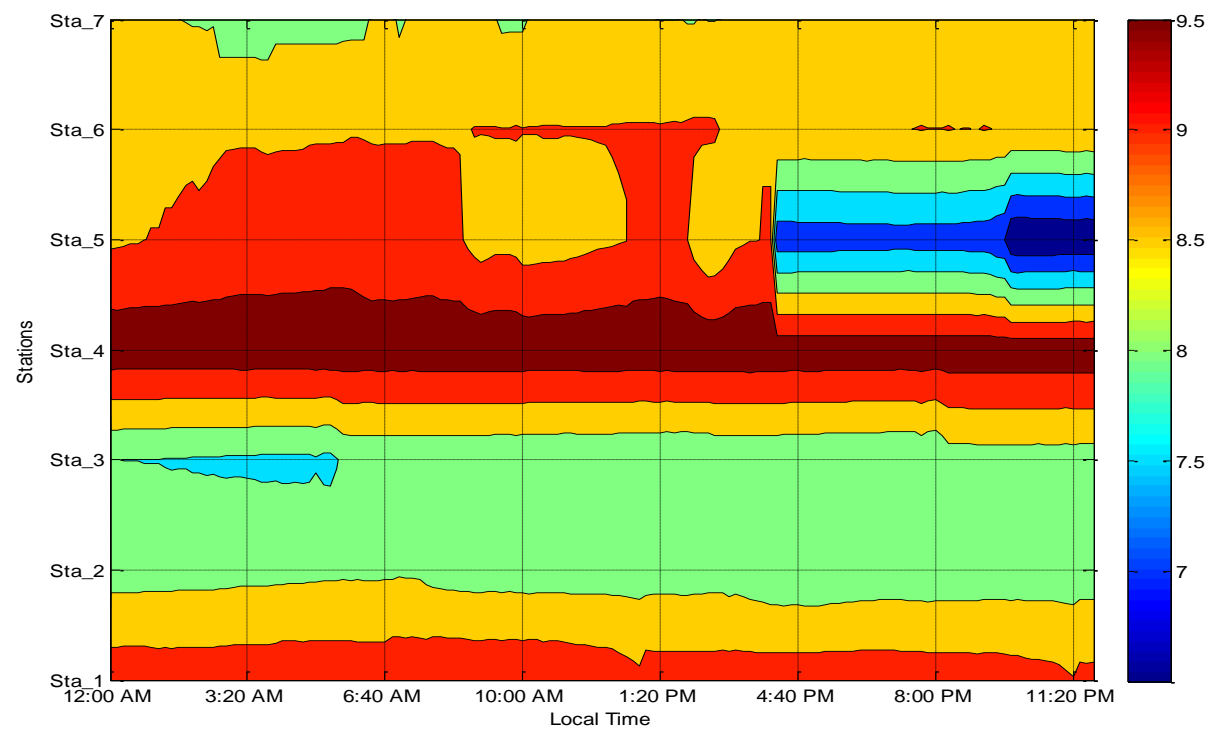

Fig.5. Diurnal variation of soil permittivity across the seven stations during the wet season

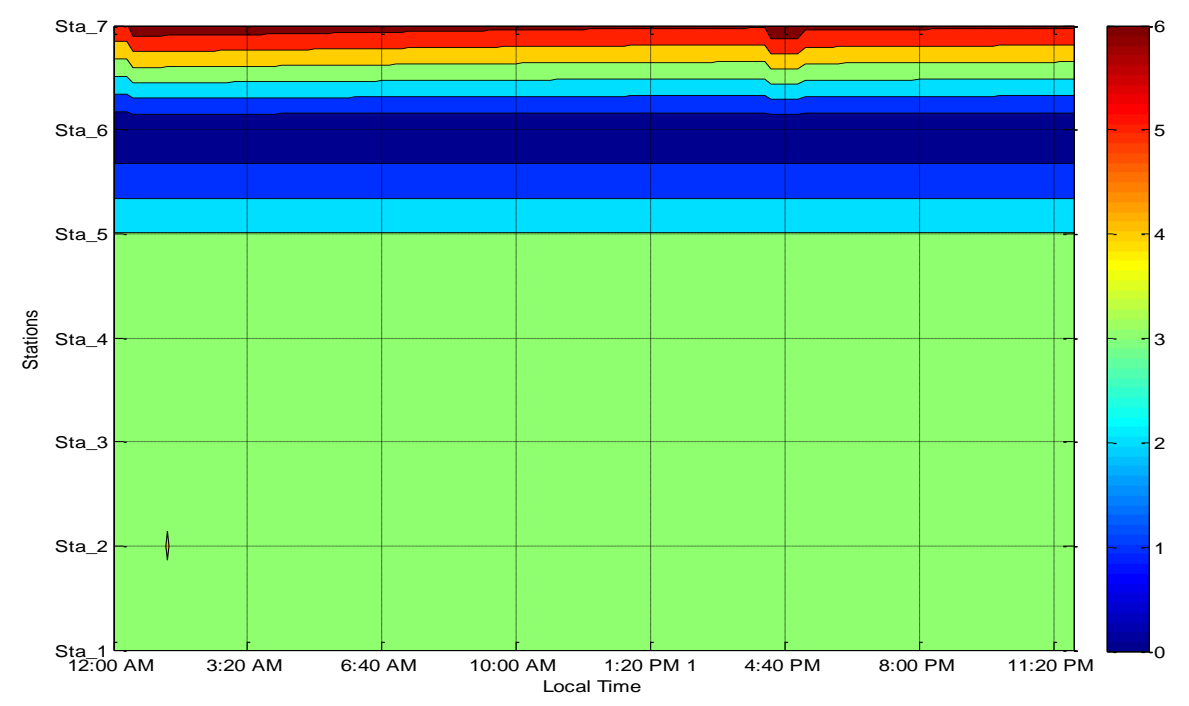

Fig.6. Diurnal variation of soil permittivity across the seven stations during the dry season

Also, the early morning hours and late evening periods of the day, synonymous with high moisture content above and within the soil layers, equally recorded higher soil permittivity values than the afternoon periods. However, there were observed sharp skews, jumps and falls which can be attributed to high resolution of the probes sensitivity. The distribution of soil permittivity at any of the locations is a reflection of one or more of the soil structure, texture and infiltration process, as well as rainfall distribution of that location $[9,25]$. Dry season distribution of soil permittivity showed that the threshold value of $3.03 \mathrm{~m}^{3} \mathrm{~m}^{-3}$ was recorded round the clock at $30 \mathrm{~cm}$ depth at most of the stations. Sta_5, Sta_6 and Sta_7 deviated from this pattern having values 
that ranged between $4.5 \mathrm{~m}^{3} \mathrm{~m}^{-3}$ and $8.5 \mathrm{~m}^{3} \mathrm{~m}^{-3}$ which reflects the ability of the soil in these locations to retain surface water more than others.

Estimating the variation of surface refractivity with soil permittivity and leaf wetness, involves correlation analysis of the variables in pairs. Table 3 shows the correlation coefficient, R, for the linear relationship of surface refractivity with soil permittivity and leaf wetness across all the stations for both wet and dry seasons.

Table 3. Correlation coefficient for the linear relationship of surface refractivity (NS) with soil permittivity (SP) and leaf wetness (LW)

\begin{tabular}{c|cc|cc}
\hline Station & \multicolumn{2}{|c|}{ Wet Season } & \multicolumn{2}{c}{ Dry Season } \\
& $\mathrm{R}(\mathrm{N}$ vs SP) & $\mathrm{R}(\mathrm{N}$ vs LW) & $\mathrm{R}$ (N vs SP) & $\mathrm{R}$ (N vs LW) \\
\hline Sta_1 & 0.5529 & 0.5614 & 0.432 & 0.4585 \\
Sta_2 & 0.2494 & 0.3395 & 0.1797 & 0.0162 \\
Sta_3 & 0.3841 & 0.2425 & 0.1992 & $2 \mathrm{E}-12$ \\
Sta_4 & 0.5608 & 0.8413 & $1 \mathrm{E}-12$ & 0.0019 \\
Sta_5 & 0.1328 & 0.7157 & 0.3743 & 0.0128 \\
Sta_6 & 0.3068 & 0.4193 & NA & NA \\
Sta_7 & 0.2776 & 0.7422 & 0.0858 & 0.1706 \\
\hline
\end{tabular}

R-values for surface refractivity (NS) with soil permittivity, (SP), ranged from 0.13 to 0.56 which reflects divergence in pattern of variation between the two parameters across different stations. Ayadi and Uso showed strong relationship with R-values of 0.55 and 0.56 respectively while Okeluse returned the weakest relationship with R-value of 0.13 , for the wet season. This may be due to occasional cessation of rain often associated with this part of the country [12,13,14 and 15]. This is also in agreement with report from rainfall distribution research in this area $[16,17,18,19,20$ and 21]. For dry season, the highest R-value of 0.43 was returned at Ayadi station while the least, came from Uso. Similarly, R-values for surface refractivity and leaf wetness ranged between 0.24 at Min of Agric and 0.84 at Uso during the wet season, while during the dry season, peak $\mathrm{R}$-value was found to be 0.46 at Ayadi. From this distribution, it is seen that the strength of association is more significant between surface refractivity and leaf wetness, than it is between surface refractivity and soil permittivity. This is so because the dynamics of surface refractivity variation is greatly influenced by changes in temperature and humidity, with pressure contributing marginally [15] and these parameters also significantly influence leaf wetness.

Table 4. Multivariate regression statistics of refractivity variation with soil permittivity and leaf wetness for all the selected stations during the wet season

\begin{tabular}{llllllll}
\hline Station & Multiple R & $R^{2}$ & Adjusted $R^{2}$ & $\begin{array}{l}\text { Standard } \\
\text { Error }\end{array}$ & Intercept & X Variable 1 & X Variable 2 \\
\hline Sta_1 & 0.59 & 0.35 & 0.34 & 3.96 & 280.80 & 5.15 & 0.73 \\
Sta_2 & 0.79 & 0.62 & 0.62 & 1.62 & 266.46 & 7.60 & -0.73 \\
Sta_3 & 0.38 & 0.15 & 0.13 & 2.50 & 384.42 & -10.49 & -0.02 \\
Sta_4 & 0.92 & 0.84 & 0.84 & 3.28 & 338.44 & -0.08 & -1.84 \\
Sta_5 & 0.86 & 0.73 & 0.73 & 3.54 & 331.10 & 1.99 & -1.66 \\
Sta_6 & 0.68 & 0.46 & 0.46 & 3.36 & -340.64 & 91.52 & -0.62 \\
Sta_7 & 0.90 & 0.81 & 0.81 & 1.36 & 196.67 & 17.98 & -0.45 \\
\hline
\end{tabular}


Tables 4 and 5 show the regression statistics of refractivity variation with soil permittivity and leaf wetness for all the selected stations during wet and dry seasons. Most stations returned good values of correlation coefficient, R, during the wet season which symbolises a good relationship in the variation patterns of the three parameters. All the stations returned positive values of regression parameters (multiple $R, R^{2}$ and adjusted $R^{2}$ ); and these values are statistically significant except Sta_3. However for the dry season the values of regression parameter, multiple $R$, were significant at stations $1,3,5$ and 7; whereas parameters $R^{2}$ and adjusted $R^{2}$ were only significant at stations 1 and 5. Similarly, standard error values were much higher in the dry season than the wet season.

Table 5. Multivariate regression statistics of refractivity variation with soil permittivity and leaf wetness for all the selected stations during the dry season

\begin{tabular}{llllllll}
\hline Station & Multiple R & $R^{2}$ & Adjusted $R^{2}$ & $\begin{array}{l}\text { Standard } \\
\text { Error }\end{array}$ & Intercept & X Variable 1 & X Variable 2 \\
\hline Sta_1 & 0.70 & 0.49 & 0.49 & 5.01 & 76.17 & 64.51 & -1.91 \\
Sta_2 & 0.12 & 0.01 & 0.00 & 4.89 & 314.02 & -4.66 & 0.21 \\
Sta_3 & 0.45 & 0.20 & 0.19 & 6.64 & 281.77 & 0.00 & 1.28 \\
Sta_4 & 0.04 & 0.00 & -0.01 & 9.40 & 268.34 & 0.00 & -0.15 \\
Sta_5 & 0.65 & 0.43 & 0.42 & 4.94 & -118.42 & 127.35 & -0.70 \\
Sta_6 & NA & NA & NA & NA & NA & NA & NA \\
Sta_7 & 0.43 & 0.19 & 0.18 & 7.51 & 304.61 & -8.05 & 6.46 \\
\hline
\end{tabular}

Evaluation of the concurrent variation in surface refractivity, soil permittivity and leaf wetness has provided insight into propagation characteristics such as ground conductivity and reflectivity; scattering and absorption by vegetation; and refraction by tropospheric inhomogeneity across the study locations. Places where high multiple-R coefficient were observed are more likely susceptible to higher signal attenuation due to the prevailing forces of deciduous absorption, ground reflection and surface refraction. Also, such phenomena will be more pronounced during the rainy season than the dry season. The individual or collective characterization of these phenomena plays significant role in microwave propagation link budgeting, and serves to improve quality of service within affected areas, hence should be accorded significant attention by radio engineers. The study also serves as databank for reconnaissance in the implementation of any wireless broadcasting scheme such as the advanced travellers' information system (ATIS) that deploys frequency in the AM to Microwave signal window.

\section{Conclusions}

In this work, the measurement of surface refractivity and its variation with leaf wetness and soil permittivity across seven (7) selected stations in Ondo State, Nigeria was carried out. Their distribution was studied on both diurnal and seasonal bases. Surface refractivity and leaf wetness were found to exhibit seasonal and diurnal variations in direct proportion to the abundance of rainfall and humidity within the earth surface. This is in agreement with the report of Falodun and Ajewole [12] and others [13, 14, and 15]. High values were recorded during the wet season and high humidity period of the day as against lower values recorded in the dry season, and high temperature periods of the day. Soil permittivity, as a function of soil moisture content, recorded higher values during the rainy season and high humid period of the day and low ones during the dry season. The correlation coefficient, $R$, values show significant positive relationship among refractivity, soil permittivity and leaf wetness at most of the stations during wet season while showing weaker relationship among the parameters during the dry season. Overall, surface refractivity exhibits diurnal and seasonal variation with soil permittivity and leaf wetness across all the stations although with varying intensities. This information is useful for microwave engineers on radio reconnaissance and communication architectural design. Adequate seasonal and diurnal consideration should be made for signal outage due to anomalous refraction, deciduous absorption 
and soil permittivity (conductivity). The information is also useful in the implementation of AM powered advanced travellers' information system (ATIS) for this region, since it provides appreciable means of quantifying the mutual distribution trend of the key attenuation factors for a microwave signal.

\section{Acknowledgements}

The authors express profound gratitude to the management of Ministry of Agriculture in Akure and the Centre for Space Research and Applications (CESRA) for their support during the process of carrying out this work.

\section{References}

[1] Hall, H.P.M. (1979): Effects of the Troposphere on Radio Communication. Peter Peregrins Ltd, U.K.\& U.S. Pp 1,22

[2] Ogunjo, S. T., Ajewole, M. O., Adediji, A. T., \& Ojo, J. S. (2014, August). Predicting radio refractivity using a stochastic model. In General Assembly and Scientific Symposium (URSI GASS), 2014 XXXIth URSI (pp. 1-4). IEEE.

[3] Adediji, A. T., \& Ogunjo, S. T. (2014). Variations in non-linearity in vertical distribution of microwave radio refractivity. Prog Electromagn Res M 36: 177-183.

[4] Sarabandi, K. (1992). Scattering from dielectric structures above impedance surfaces and resistive sheets. IEEE transactions on antennas and propagation, 40(1), 67-78.

[5] Gadani, D. H., \& Vyas, A. D. (2008). Measurement of complex dielectric constant of soils of Gujarat at $\mathrm{X}$-and C-band microwave frequencies. 77.22. $\mathrm{Gm}$.

[6] Ajayi, G.O. (1989): Physics of the Tropospheric Radio Propagation. A proceeding of the ICTP College on Theoretical and Experimental Radio Propagation Physics, Trieste, Italy, 6-24.

[7] Allen, E. W. (1975): Wave Propagation, Radiation and Absorption. NAB Engineering Handbook, $6^{\text {th }}$ edition.

[8] Barringer, M. (1980): Radio Wave Propagation. NAB Engineering Handbook

[9] Ajewole, M. O., \& Arogunjo, A. M. (2000). Measurement of Ground Electrical Conductivity for Planning Medium Wave Radio Broadcast Stations in South Western Nigeria. Nigeria Journal of Pure and Applied Physics, 1(1), 11-16.

[10] Owolabi I.E (1987): Tropospheric Radio wave propagation. Proc. International workshop on electromagnetic waves and applications, university of Ilorin, 1978, pp54-69.

[11] Willoughby, A. A., Aro, T. O., \& Owolabi, I. E. (2002). Seasonal variations of radio refractivity gradients in Nigeria. Journal of Atmospheric and Solar-Terrestrial Physics, 64(4), 417-425.

[12] Falodun, S. E., \& Ajewole, M. O. (2006). Radio refractive index in the lowest 100-m layer of the troposphere in Akure, South Western Nigeria. Journal of Atmospheric and Solar-Terrestrial Physics, 68(2), 236-243.

[13] Adediji, A. T., \& Ajewole, M. O. (2008). Vertical Profile of Radio Refractivity Gradient in Akure SouthWest Nigeria. Progress In Electromagnetics Research, 4, 157-168.

[14] Adediji, A. T., \& Ajewole, M. O. (2010). Microwave anomalous propagation (AP) measurement over akure south western Nigeria. Journal of Atmospheric and Solar-Terrestrial Physics, 72(5-6), 550-555.

[15] Adediji, A. T., Ajewole, M. O., Ojo, J. S., Ashidi, A. G., Ismail, M., \& Mandeep, J. S. (2015). Influence of some meteorological factors on tropospheric radio refractivity over a tropical location in Nigeria. Mausam, 66(1), 123-128.

[16] Ojo, J. S., \& Sarkar, S. K. (2008). Rainfall dynamics over two Indian tropical stations for radio communication. International Journal of Infrared and Millimeter Waves, 29(7), 649. 
[17] Ojo, J. S., \& Okeowo, R. C. (2008). The application of 3D rain scatter model on horizontally polarized shf signal propagation in tropical location. International Journal of Infrared and Millimeter Waves, 29(12), 1136.

[18] Mandeep, J. S., Ojo, J. S., \& Emiliani, L. D. (2009). Statistics of annual and diurnal cloud attenuation over equatorial climate. IET communications, 3(4), 630-635.

[19] Ojo, J. S., Ajewole, M. O., \& Emiliani, L. D. (2009). One-minute rain-rate contour maps for microwavecommunication-system planning in a tropical country: Nigeria. IEEE Antennas and Propagation Magazine, 51(5).

[20] Ojo, J. S., Ajewole, M. O., \& Sarkar, S. K. (2010). Statistical characterizations of rainfall structure over two tropical stations in southern India for microwave communication. Theoretical and applied climatology, 101(3-4), 363-369.

[21] Ojo, J. S., \& Omotosho, T. V. (2013). Comparison of 1-min rain rate derived from TRMM satellite data and raingauge data for microwave applications in Nigeria. Journal of Atmospheric and Solar-Terrestrial Physics, 102, 17-25.

[22] Wang, J. R., \& Schmugge, T. J. (1980). An empirical model for the complex dielectric permittivity of soils as a function of water content. IEEE Transactions on Geoscience and Remote Sensing, (4), 288-295.

[23] Vyas, A. D. (1982). Complex permittivity of sand \& sandy loam soils at microwave frequency.

[24] Hallikainen, M. T., Ulaby, F. T., Dobson, M. C., El-Rayes, M. A., \& Wu, L. K. (1985). Microwave dielectric behavior of wet soil-part 1: Empirical models and experimental observations. IEEE Transactions on Geoscience and Remote Sensing, (1), 25-34.

[25] Adedayo, K. D., Ajewole, M. O., Ogunjo, S. T. and Agboola, O. (2013). Measurement of soil Nigeria. Journal of Nigeria Association of Mathematical Physics, 23:503 - 510

[26] Vernier, D. (2007). Propagation Characteristics of Radio Waves. In National Association of Broadcasters Engineering Handbook (Tenth Edition) (pp. 95-109).

[27] Balogun, I. A., Adeyewa, D. Z., Balogun, A. A., \& Morakinyo, T. E. (2011). Analysis of urban expansion and land use changes in Akure, Nigeria, using remote sensing and geographic information system (GIS) techniques. Journal of Geography and Regional Planning, 4(9), 533-541.

[28] Topp, G. C., Davis, J. L., \& Annan, A. P. (1980). Electromagnetic determination of soil water content: Measurements in coaxial transmission lines. Water resources research, 16(3), 574-582.

[29] Nagelkerke, N. J (1991). A note on a general definition of the coefficient of determination. Biometrika, 78(3), 691-692

[30] Rao, C. R. (1973). Linear Statistical Inference and its Applications, 2nd ed. New York: Wiley.

[31] Asuero, A. G., Sayago, A., \& Gonzalez, A. G. (2006). The correlation coefficient: An overview. Critical reviews in analytical chemistry, 36(1), 41-59.

[32] Abdi, H., \& Williams, L. J. (2007). Coefficients of correlation, alienation and determination. Encyclopedia of Measurement and Statistics. Sage, Thousand Oaks, CA.

[33] Lapin L. L., 1990, Probability and statistics for modem engineering, PWS-KENT Publ Co., Boston, USA

\section{Authors' Profiles}

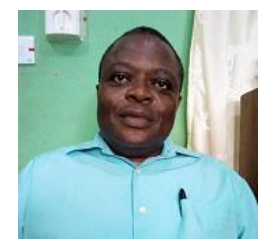

K. D. Adedayo is a Professor with the Department of Physics, Federal University of Technology, Akure. He holds a Bachelor of Technology (B.Tech), Master of Technology (M.Tech) and Doctor of Philosophy (PhD) degrees in Physics from the same institution. His field of research is in electronic measurement, instrumentation and radio communication. 

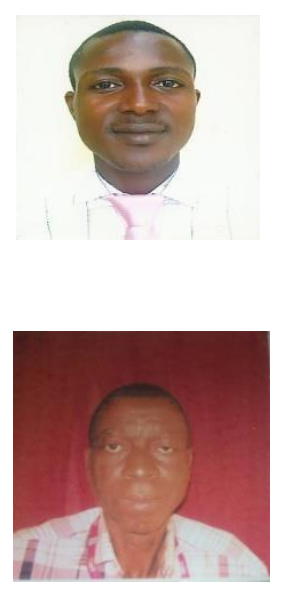

Ashidi A. G. is a young scientist with the Department of Physics, Federal University of Technology, Akure. He holds a Bachelor of Technology (B.Tech) and Master of Technology (M.Tech) degrees in Physics from the same institution and $\mathrm{He}$ is at an advanced stage on his PhD. His field of research is in Communication Physics and Radio Science.

Oni S. A. is faculty member at the Department of Physics, College of Education, IkereEkiti, Ekiti State, Nigeria. He holds a Higher National Diploma (HND) in Physics/ Electronics, from Federal Polytechnic Ado Ekiti, Ekiti State; Postgraduate Diploma (PGD) and Master of Technology (M.Tech) from the Federal University of Technology Akure. His field of research is radio communication.

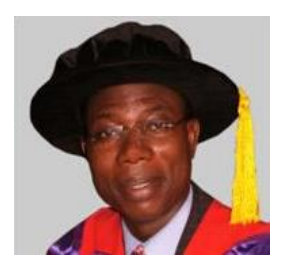

Ajewole M. O. is a Professor of Communication Physics and Radio Science with The Federal University of Technology, Akure. He holds a Bachelor of Science (BSc) and Master of Science (MSc) degrees from the University of Ilorin; and Doctor of Philosophy $(\mathrm{PhD})$ degree from the Federal University of Technology, Akure. His field of research is in radio science and communication physics.

How to cite this paper: Adedayo Kayode, Ashidi Ayodeji, Oni Samuel, Ajewole Moses, "Variation of Surface Refractivity with Soil Permittivity and Leaf Wetness in a Tropical Location", International Journal of Wireless and Microwave Technologies(IJWMT), Vol.9, No.4, pp. 26-38, 2019.DOI: 10.5815/ijwmt.2019.04.03 